\title{
The impact of aging on cancer burden in people with HIV/AIDS
}

Jerry Polesel ${ }^{1 *}$, Silvia Franceschi ${ }^{2}$, Barbara Suligoi $^{3}$, Eugenio Paci for AIRTUM ${ }^{4}$, Antonella Zucchetto', Diego Serraino", Luigino Dal Maso ${ }^{1}$

From $12^{\text {th }}$ International Conference on Malignancies in AIDS and Other Acquired Immunodeficiencies (ICMAOI)

Bethesda, MD, USA. 26-27 April, 2010

\section{Background}

People with HIV/AIDS (PWHA) have higher risk of some cancers compared to the general population, with an approximately 2-fold increase for all non-AIDS-defining cancers (NADC). The widespread use of highly active antiretroviral therapy (HAART) has improved life expectancy of PWHA, exposing them to both aging and the prolonged exposure to cancer risk factors. A linkage study was therefore conducted to evaluate the impact of aging on the burden of cancer in this population.

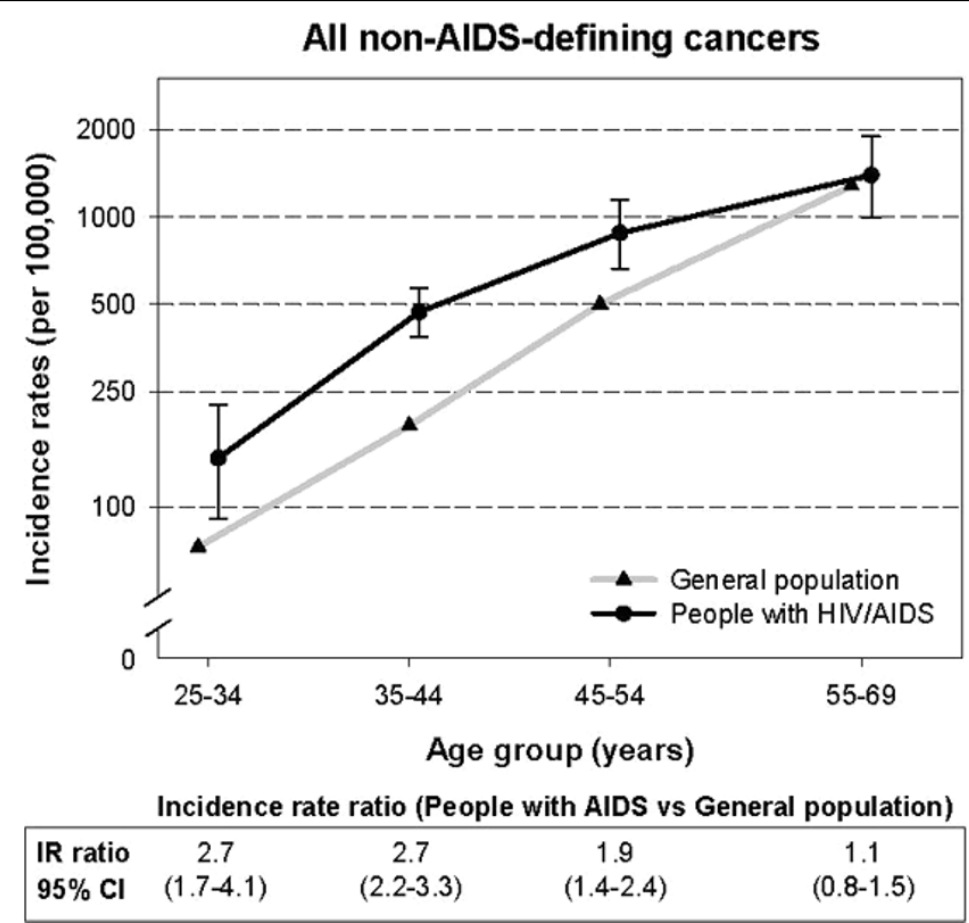

Figure 1 Age-specific incidence rates of non-AIDS-defining cancers in people with HIV/AIDS and in the general population.

\footnotetext{
*Correspondence: polesel@cro.it

'Cancer and AIDS Registries Linkage Study, Unit of Epidemiology and

Biostatistics, IRCCS Centro di Riferimento Oncologico, Aviano, Italy

Full list of author information is available at the end of the article 
Table 1 All non-AIDS-defining cancers

\begin{tabular}{llll}
\hline $\begin{array}{l}\text { Age Group } \\
\text { (years) }\end{array}$ & $\begin{array}{l}\text { Incidence Rates } \\
\text { (per 100,000) }\end{array}$ & $\begin{array}{l}\text { General Population People } \\
\text { With HIV/AIDS }\end{array}$ & $\begin{array}{l}\text { Incidence Rate Ratio (people with AIDS vs. general } \\
\text { population) IR Ratio }\end{array}$ \\
\hline $25-34$ & 100 & $2.7(1.7-4.1)$ & $95 \% \mathrm{Cl}$ \\
$35-44$ & 250 & $2.7(2.2-3.3)$ & \\
$45-54$ & 500 & $1.9(1.4-2.4)$ & \\
$55-69$ & 1000 & $1.1(0.8-1.5)$ & \\
& 2000 & & \\
\hline
\end{tabular}

\section{Materials and methods}

We performed an anonymous record linkage between Italian AIDS (21,951 cases) and Cancer Registries (17.3 million people, covering $30 \%$ of the general population). Crude incidence rates (IR), IRs directly standardized by sex and age, and age-specific IRs were estimated for NADCs in the pre-HAART (1986-1996) and in the HAART (1997-2004) periods.

\section{Results}

Crude IRs of NADCs increased $78 \%$ from pre-HAART to HAART period (IRs: 287 and 496 per 100,000, respectively). However, when aging of PWHA was taken into account through standardization, no difference emerged (standardized IRs: 352 and 379 per 100,000, respectively). Concerning specific cancer site/type, standardized IRs revealed an increase of liver (from 6 to 26 per 100,000; IR ratio: 4.6, 95\% confidence interval, CI: 1.3-17.0) and lung cancers (from 37 to 65 per 100,000; IR ratio: 1.8 , 95\% CI: 1.0-3.2). No significant variation across periods emerged for Hodgkin lymphoma (IRs: 83 and 69 per 100,000 in pre- and HAART period; IR ratio: 0.8, 95\% CI: 0.5-1.3). IRs of NADCs increased with age from 147 per 100,000 in PWHA aged 25-34 years to 1396 per 100,000 in those aged $55-69$ years (Figure 1 ); however, the rise was smoother than in the general population. As a consequence, the excess of NADCs risk declined with age, peaking in PWHA aged 2544 years (IRs ratio: 2.7) and disappearing in the oldest age group (IRs ratio: 1.1; 95\% CI: 0.8-1.5). (Table 1)

\section{Conclusions}

The lack of any change in standardized IRs of NADCs across periods highlights the strong influence of PWHA aging on the observed upward trends of crude IRs. The aging of PWHA in HAART period, together with the age-related increase of cancer incidence, points to cancer as an increasing medical priority for this population in the near future. This calls for the intensification of cancer prevention strategies, notably smoking cessation and screening programs.

\section{Acknowledgements}

This article has been published as part of Infectious Agents and Cancer Volume 5 Supplement 1, 2010: Proceedings of the $12^{\text {th }}$ International Conference on Malignancies in AIDS and Other Acquired

Immunodeficiencies (ICMAOI). The full contents of the supplement are available online at http://www.biomedcentral.com/1750-9378/5?issue=S1.

\section{Author details}

${ }^{1}$ Cancer and AIDS Registries Linkage Study, Unit of Epidemiology and Biostatistics, IRCCS Centro di Riferimento Oncologico, Aviano, Italy. ${ }^{2}$ International Agency for Research on Cancer, Lyon, Italy. ${ }^{3}$ Department of Infectious Diseases, National Institute of Health, Rome, Italy. ${ }^{4}$ Italian Association of Cancer Registries, Florence, Italy.

Published: 11 October 2010

\section{doi:10.1186/1750-9378-5-S1-A78}

Cite this article as: Polesel et al.: The impact of aging on cancer burden in people with HIV/AIDS. Infectious Agents and Cancer 2010 5(Suppl 1): A78.
Submit your next manuscript to BioMed Central and take full advantage of:

- Convenient online submission

- Thorough peer review

- No space constraints or color figure charges

- Immediate publication on acceptance

- Inclusion in PubMed, CAS, Scopus and Google Scholar

- Research which is freely available for redistribution

Submit your manuscript at www.biomedcentral.com/submit 